\title{
CONFESSIO AMANTIS
}

POR

\author{
ALFRED J. MacADAM \\ Barnard College-Columbia University
}

Asociar Confessio Amantis, el didáctico poema medieval de John Gower, con la obra de Guillermo Cabrera Infante puede parecer frívolo. Sin embargo, Confessio Amantis emplea una serie de recursos parodiados en los libros de Cabrera Infante, en particular en Tres tristes tigres y La Ilabana para un infante difunto ${ }^{1}$. Este paralelo entre un autor del siglo XIV y un contemporáneo nuestro no debe interpretarse como una tentativa de negar la relación del texto con su mundo, sino como una comparación de las estructuras de un género.

El estudio de los géneros, con sus definiciones arbitrarias, resulta pedante si lo tomamos como una búsqueda de absolutos. Declarar que tal obra es una novela o que tal otra es una sátira no significa nada, a menos que la designación mejore nuestra lectura de un texto cambiando nuestro horizonte de expectativas. Los géneros nos informan de lo que podemos exigir del texto, al mismo tiempo que nos dan una lista de normas sumamente susceptibles a la parodia. Aristóteles evidentemente creía que valía la pena distinguir entre tragedia y comedia, y el mismo deseo de precisión puede aplicarse a la prosa.

Fijar los parámetros para todos los géneros sería multiplicar las categorías hasta el absurdo, y es más práctico hablar de tendencias. Es decir, muchas veces un libro no pertenece totalmente a ningún género específico, pero sí tiende hacia uno u otro. El estudio de la literatura no es la metalurgia: no encontramos las sustancias en su forma pura y no es nuestra tarea purificarlas.

El estudio de los géneros es esencialmente didáctico y en este sentidorefleja uno de los elementos compartidos tanto por la literatura medieval, el Confessio Amantis por ejemplo, y la narrativa latinoamericana de los sesenta. Una de las apologías por la literatura más repetidas durante la Edad Media es que por medio de historias divertidas el autor puede enseñar doctrinas importantes. La novela del boom también enseña, pero su doctrina tiene más que ver con el arte, la filosofía, o la crítica social, que con la salvación o la Santísima Trinidad. Es como si los autores pensaran que sin el subtexto pedagógico, sus libros resultarían excesivos para los lectores.

${ }^{1}$ Guillermo Cabrera Infante, Tres tristes tigres (Barcelona: Scix Barral, 1967). La Habana para un infanle difunto (Barcelona: Seix Barral, 1979). Todas las citas son de estas ediciones. 
Rayuela (1963), que estructuralmente se parece a Tres tristes tigres, es un buen ejemplo. Entremezclada con las crisis de Horacio Oliveira encontramos en los capítulos sobre la muerte de Morelli una larga meditación sobre cómo hay que escribir una novela en nuestra época. Rayuela resulta un texto enciclopédico: una novela, una especulación estética sobre la novela como género, y materia cruda (los "capitulos prescindibles") para una novela.

Es muy probable que la primera versión de Tres tristes tigres, el manuscrito titulado Vista del amanecer en el trópico, que ganó el premio de la Biblioteca Breve en 1964, se parecía a Rayuela. La novela de Cortázar consiste de cincuenta y seis capítulos consecutivos, entre los cuales aparecen, como digresiones o alternativas, docenas de otros capítulos. Es un texto doble, alternante, en que vamos de un tipo de lectura a otro. Otros textos de Guillermo Cabrera Infante confirman esta noción: El libro titulado Vista del amanecer en el trópico (1974) consiste de escenas de la historia cubana, descripciones de grabados antiguos o incidentes dramáticos, desde la conquista hasta la época de Fidel Castro. Estos capítulos, en el manuscrito original, habrían sido el texto alternativo, y el lector habría pasado desde las aventuras nocturnas de Arsenio Cué y Silvestre Isla hasta la violencia que es la historia cubana.

La misma técnica aparece en los cuentos recopilados en Asi en la paz como en la guerra (1960), libro al parecer inspirado por In Our Time (1924) de Ernest Hemingway. En este libro, donde aparece por primera vez el personaje Silvestre, el lector lee, alternativamente, escenas de violenta represión política y escenas domésticas o realistas de la vida cubana prerevolucionaria. La historia y la vida privada son dos espejos enfrentados.

Cabrera Infante nunca ha descrito claramente la estructura primitiva de Tres tristes tigres, pero sabemos que el libro que leemos hoy es muy diferente al manuscrito premiado. El autor ha dicho que añadió los capítulos de Bachata después de salir definitivamente de Cuba en 1965 y que hubo cambios en el manuscrito hechos por el censor del General Franco:

ENT. ¿Nos puede hablar de la publicación de TTT', como nació con el título Vista del amanecer en el trópico?

GCI. Es una historia muy sencilla. El libro que ganó el premio de la Biblioteca Breve en 1964 fue prohibido por los censores de Franco. Esto ocurrio cuando me detenían a la fuerza en Cuba durante 1965. Fue entonces cuando empecé a repensar el libro. Comencé a jugar con la idea de cambiarlo y escribí lo que es ahora el fragmento final, "Bachata". Cuando al fin logré salir de Cuba, descubrí lo que había pasado en España con el viejo manu scrito. Lo escribi de nuevo alli mismo con el nuevo título, que fue el título que tenía antes de ganar el premio. El censo hizo algunos cortes, pero hubo tambien mucha reescritura. ENT. Por lo que dices se puede pensar que cl censor fue también un corrector. GCI. Es cierto, el censor español fue más imaginativo que los correctores de la casa editorial. Hizo veintidós cortes, los más relacionados a los senos femeninos. Si yo tenía "tetas", él las cambió por "senos". Eliminó toda referencia 
al sexo oral -aunque no abundan estas cosas en TTYT, libro bastante casto sobre la amistad y no sobre el sexo. Pero el censor estaba preocu pado con otras cosas tambien, en particular cuando se trataba de hombres, asi que si un personaje fue alu mno en una academia militar y resultó homosexual después, el censor tranquilamente borró la palabra "militar". Mis academias entonces son más platónicas que prusianas. Es al final que el censor muestra su talento. El final es un discurso largo de una loca que yo habra copiado años antes y que ahora usaba como un epílogo. La vieja hablaba sin cesar y siempre se repetía. Fue una fanática religiosa, maldecía el catolicismo, el papa, y los curas. El censor cortó todo aquello y aś eliminó todo lo que era repetitivo y neorealista en el discurso. La última frase en su versión, todo en minúsculas y sin puntuación fue "ya no se puede más". ¿Hay mejor manera para terminar un libro? ${ }^{2}$

Hay también pequeñas diferencias entre la primera edición de Tres tristes tigres y las más recientes (los derechos del autor datan de 1965, pero los primeros cinco mil ejemplares no fueron impresos hasta 1967). Un ejemplo: El personaje Cuba Vanegas originalmente se llamaba Minerva Eros.

En todo caso, lo que habria hecho de Tres tristes tigres un comentario sobre la historia cubana hasta el momento de la revolución fue cortado por el autor al salir de Cuba. La política casi desaparece del libro, y Cuba se transforma en una realidad lingüística. El libro es más literario en la versión que leemos, más una meditación sobre el amor, la amistad y la traición, y menos un estudio de Cuba. El desengaño político de Cabrera Infante con respeto a la revolución cubana lo obligó a purgar la historia y el realismo literario de su texto y orientarlo hacia la literatura carnavalesca que Bajtín describe en sus libros sobre Dostoievski y Rabelais —una literatura satírica, paródica, "un espectáculo sincrético de tipo ritual"s.

Pero no hay que tomar demasiado en serio lo que dice Cabrera Infante sobre sus propios libros. Por ejemplo, la nota sobre el autor que aparece en la tapa de la primera edición de Tres tristes tigres dice, "Ahora vive en Londres con su mujer, dos hijas del matrimonio anterior y un manuscrito que lleva el título provisional de Itaca vuelta a visitar". Cabrera Infante no ha publicado nunca un libro así titulado, aunque Itaca, metáfora para Cuba, aparece frecuentemente en sus ensayos y discursos.

El próximo libro importante de Cabrera Infante, al parecer, tenía también varios títulos:

GCI: El título es siempre lo primero, para mí y para el lector. He cscrito muchos cuentos y artículos a base de un título. Algunas veces utilizo un título provisional, otras veces encuentro un título apto para el tema. La Habana para

\footnotetext{
2 "The Art of Fiction LXXV, Guillermo Cabrera Infante", Paris Review, n. 87, Spring, 1983: xxx-xxx. La traducción de las citas es mía.

${ }^{3}$ Mikhail Bakhtin, Problems of Dostoevsky's Poetics, ed. and trans., Caryl Emerson, Theory and History of Literature, vol. 8 (Minneapolis: University of Minnesota Press, 1984) 122.
} 
un infante difunto por ejemplo tenía otro título cuando empecé a escribirla: Las confesiones de agoslo, una alusión traviesa a la confesión y a las Confesiones de San Agustín. Había empezado a escribir en agosto, así que aquéllo estaba también incluído. Entonces, un día of un título, La Habana para un infanle difunto, asi, de la misma manera en que San Agustín oyó la voz en el jardín. Con el nuevo título, escribí todo el libro de nuevo. (Paris Review, pp. 169-170)

¿Podemos, debemos, tomar todo esto en serio? No, porque Cabrera Infante es un autor que "escribe" constantemente - ahora en forma novelesca, ahora en una carta personal, ahora en una entrevista. La entrevista citada aquí fue escrita; algunas partes eran originalmente orales, pero el texto final fue escrito y corregido como un texto escrito. Para Cabrera Infante, escribir es crear ficciones, mentiras, falsificaciones, y ocultar lo estéticamente o personalmente desagradable. Puede haber verdad en lo escrito, pero su función es secundaria. Lo importante es parodia y paronomasia.

Esto explica mucho de lo que pasa en Tres tristes tigres. Nosotros experimentamos el texto como palabras escritas, y el libro mismo se empeña en señalar que la palabra escrita es palabra muerta. Dentro del sarcófago verbal está la memoria de la palabra viva - de la misma manera en que los egipcios romanizados de la ciudad de Fayún ${ }^{4}$ colocaban un retrato del muerto al sarcófago de sus difuntos. Los sarcófagos no fueron enterrados, de manera que los parientes podían visitar a sus muertos y hablar con ellos dirigiéndose a los retratos. Los retratos eran muy realistas, a diferencia del arte tradicional egipcio, así que los muertos se salvaron por medio de mimesis. El doble textual de estos retratos funerarios sería un poema como Dei sepolcri, por Ugo Foscolo. Como dice Eugenio Donato, "La memoria también es esencialmente textual; un texto desplazado y reescrito por el poema, que gana su voz de lo hueco de las tumbas, que sirven, si me permiten la metáfora, como tablas de armonia". La tumba hueca, el significante separado del significado, sólo resuena cuando la voz del lector le da vida; el tex to silencioso no es más (como señala Donato) que una pirámide derrideana. Conviene recordar que Cabrera Infante nos insta, en su "Advertencia", a leer su libro en voz alta: "algunas páginas se deben oír mejor que se leen, y no sería mala idea leerlas en voz alta".

Tres tristes tigres es una pirámide verbal, la representación sistemática de la incapacidad del signo escrito de retener la palabra hablada. Y la escritura entonces es falsificación y traición, como lo dice el mismo autor:

Mi primer libro importante, Tres tristes tigres, trata la amistad, y La Habana trata el amor, la biografia de un personaje en busca del coito perfecto. Pero en los dos libros el desengaño dura más que el amor. En TTT, la amistad crea la

- Octavio Paz, en su ensayo sobre el pintor Hermenegildo Bustos (1832-1907), compara los retratos de este mexicano del siglo XIX con los retratos funcrarios de Fayún: "I, a Painter," FMR, vol. 8 (enero-febrero, 1985), ver especialmente las páginas 79 y 84 .

${ }^{5}$ Eugenio Donato, "The Mnemonics of History: Notes for a Contextual Reading of Foscolo's Dei Sepolcri”, Yale Italian Studies: 22-23. 
traición y en La Habana, antes de que las flores del sexo se marchiten, el sexo mismo decae. (Paris Review, p. 170)

Luego añade:

Después de todo, la traición es lo más importante de TTT: la traición de la vida por medio del lenguaje y la literatura. La traición más grave es la traducción, de la literatura, del lenguaje, de la vida. ¿Por qué, entonces, no traicionar también las expectativas del lector? (Paris Review, p. 171)

¿Quién traduce en TTT? Rine Leal traduce la historia de los Campbell que el lector toma por un incidente real hasta que aparece como un manuscrito (un texto dentro de otro texto) en el bolsillo de Silvestre (pp. 438-9). Pero vemos que todo TTT se basa en el principio de la traducción, del español hablado al español escrito, del lenguaje vivo a la letra muerta: La cantante de boleros Estrella y el maestro lingüístico Bustrófedon, los dos manipuladores del lenguaje oral, mueren en el libro. Todo lo que queda de Estrella es un disco malo; todo lo que queda de Bustrófedon son las parodias llamadas "La muerte de Trotsky referida por varios escritores cubanos, años después-o antes", que Arsenio Cué trata de grabar. Las historias de los dos son narradas por Códac, cuya técnica personal para traducir/traicionar es la cámara; pero sabemos que lo que estamos leyendo es la versión de lo que dicen los demás o lo que cuenta un personaje específico en su propia voz.

¿Hasta qué punto entonces compromete el hecho de ser Silvestre Isla el portavoz de Cabrera Infante lo que muchos críticos han visto como uno de los rasgos esenciales de TTT - su dialogismo? Si pensamos en este término, tal como Bajtin lo emplea en Problemas de la poética de Dostoievski, podemos tener algunas dudas. Bajtin dice que:

La novela de Dostoievski es dialógica. Está construida no como la totalidad de una conciencia única que absorbe otras conciencias como si fueran objetos, sino como una totalidad formada por la interacción de una pluralidad de conciencias, ninguna de las cuales se transforma en objeto para las otras; esta interacción no apoya al lector que de otra manera pueda objetificar un hecho según alguna categoría monológica (temática, lírica, o cognificativamente) y esta situación transforma al lector en partícipe. La novela no sólo no da apoyo firme fuera del mundo frágil del diálogo para una tercera, totalizante, monológica conciencia, sino que, al contrario, la novela entera está estructurada para hacer una oposición dialógica includible. No hay ningún elemento de la novela estructurada desde el punto de vista de una tercera persona externa. En la novela, no hay terceras personas. No hay lugar para ellas, ni en la composición, ni en el significado más amplio de la obra. Y esto no es una. debilidad del autor sino su fuerza. Por medio de esta téenica, el autor gana conquista una nueva perspectiva, una que está por encima de la perspectiva monológica. (Dostoievski, p. 18) 
En su estudio comparativo de Guimarães Rosa y Cabrera Infante, Stephanie Merrim arguye que $T T T$ es una novela dialógica porque es una parodia (ella también se basa en Bajtín):

El lenguaje monológico, de una sola voz, está casi ausente de TTT. Para convertir el lenguaje hablado en lenguaje literario, Cabrera Infante declara que ha transferido el discurso desde el plano horizontal hasta el plano vertical, aumentando las resonancias de la palabra .... El resultado de la transferencia fue que el lenguaje monológico fue reemplazado por el shaz dialógico, por la intertextualidad, la parodia, todo lo cual hace que el lenguaje de Cabrera Infante sea eminentemente auto-conciente-literario- un lenguaje que alude menos a un contexto real o a un referente que a un interlexto. Otra vez descubrimos que el hueco entre el significante y el significado, con énfasis el significante y su pasado literario que hace eco del concepto bajtiniano del carácter intertextual de la palabra ${ }^{6}$.

Las aseveraciones de Merrim en cuanto a Cabrera Infante son exactas, igual que sus observaciones sobre el final de la novela, donde Silvestre, por medio de su amor por Laura, rompe con Cué y empieza a construir su propia identidad. El problema es Silvestre, el autor dentro del texto el tradittore, la inteligencia que gobierna la totalidad.

Es aquí donde tenemos que considerar Confessio Amantis y John Gower. El poema de Gower está clasificado, junto con el libro epónimo de Boecio, como una "consolación". Para ver la relevancia de esta forma en Cabrera Infante, habría que añadir la observación sobre Boecio hecha por Bajtín, que la Consolación es la culminación "del desarrollo de la sátira al estilo de Menipeo durante la antiguedad". (Dostoievski, p. 113) Gower modifica la estructura de la Consolación, el diálogo, de manera que en vez de encontrar al principio del libro un autor-narrador, como Dante en la Commedia o Petrarca en el Secretum, encontramos una figura alegórica que se llama Amans (el amante transformado en participlo activo).

El narrador, que se llama John Gower, está, al principo, enfermo de amor; quiere morir, pero también busca ayuda. Luego aparece Venus, que ha oído sus lamentos, y le pregunta, "¿Quién eres, hijo?" Gower no sabe contestar, naturalmente, y ella empieza a ayudarlo enviándole un personaje que se llama Genius, que combina lo mejor de una computadora y un siquiatra. Genius, a su vez, le manda otras figuras que reflejan apectos de Amans, que dialogan con ellas. Estos diálogos y los diálogos que Amans Gower tiene consigo mismo tienen el mismo efecto que un sicoanálisis: Al final del Confessio, Amans está sano. Está completo porque ha recuperado su identidad: Cuando Venus le pregunta (Libro VIII) quién es, contesta "John Gower".

\footnotetext{
6 Siephanie Merrim, "Logos and the Word: the Novel of Language and Linguistic Motivation in 'Grande Sertão: Veredas' and "Tres Trisles Tigres", Utah Studies in Litcrature and Linguistics, vol. 23 (New York: Peter Lang, 1983) 66-67.
} 
La estructura de la obra es muy flexible: Su trama es la recuperación de su identidad por Amans, así que se permiten toda clase de digresiones y meditaciones sobre la historia y la mitología. El recurso literario de la pérdida y la recuperación de la identidad deriva del romance, donde los personajes frecuen. temente están disfrazados físicamente $-\mathrm{y}$ no trastornados sicológicamente como en Gower-y que al final de su historia se quitan sus máscaras y toman su lugar correcto en el mundo. Como dice Northrop Frye, cuando el protagonista recobra su identidad, no hay más que decir: "La palabra identidad quiere decir muchas cosas, pero todos sus significados en romance están relacionados con un estado sobre el cual no hay nada que escribir" ${ }^{m 7}$. Pero Confessio Amantis es una confesión, y la confesión (penitencia) para Gower fue un sacramento, una manera de conseguir la gracia. Confesar es explorarse, averiguar quiénes somos, y esto exige que sepamos quiénes éramos.

Confesión es autobiografía, el ejercicio de la memoria en la reconstrucción del yo: sólo por medio de la memoria es posible recuperar la salud -o, en el caso de Cabrera Infante, escribir. En los momentos finales del poema de Gower, el amante mira en el espejo y encuentra a un viejo. El espejo ya no simboliza la vanidad o el narcisismo, sino el desengaño. Vale la pena notar que la memoria para Gower se extiende más allá del individuo para abarcar también la sociedad, que recordar el pasado para encontrarse a sí mismo y analizar la historia humana para entender al hombre son actos paralelos.

Es en este sentido que debemos leer TTT como una consolación-confesión, un texto en que un personaje, Silvestre, logra salir de un confuso laberinto verbal, un mundo donde el lenguaje lo enajena al mismo tiempo que lo divierte. Su consuelo deriva de hechos memorables: Lo que aprende de sus amigos, las lecciones que va redactando en el libro que nosotros leemos. El énfasis aquí está en la redacción de lo escuchado, realizada por Silvestre, y su manera de arreglarlo en un orden. Hay consuelo en el acto de redactar algo que desaparece (la vida nocturna habanera, lingüísiticamente fascinante y peligrosa) se conserva, al menos en forma escrita.

El primer amor de Silvestre es el lenguaje, su segundo amor es el cine, su tercer amor es Laura Díaz. El amor del lenguaje (o de la literatura o del cine) es un proceso que enajena a Silvestre de la misma manera en que el amor impuro enajena a Gower. Vemos esta enajenación en sus compañeros - sus dobles. No producen nada; son impotentes o estériles. La homosexualidad en TTT es una metáfora, una forma de narcisimo y un rechazo de relaciones humanas basadas en algo más que las palabras o la lujuria.

Lo que no experimentan los amigos de Silvestre es el amor. Parece sentimental recordar este tema en un libro que ridiculiza tantas cosas serias, pero el hecho trascendental en la vida de Silvestre es su amor: El poeta ama a

\footnotetext{
${ }^{7}$ Northrop Frye, The Secular Scripture: a Sludy of the Structure of Romance (Cambridge: Harvard Univ. Press, 1976) 54.
} 
Laura. En el capítulo XIII de Bachata, Cué y Silvestre encuentran un corazón con las iniciales $\mathrm{G} / \mathrm{M}$ escritos en la puerta de un baño. Ellos no nos dicen que estos amantes son Guillermo Cabrera Infante y Miriam Gómez; es el mismo autor comentando la importancia del amor en el texto: Amor omnia vincit. El autor se coloca a sí mismo en su texto para señalar que él también está enamorado. Por supuesto, el "Guillermo" del libro tiene un parentesco cercano con Pierre Menard, como vemos cuando aparece en el capítulo XXI, en una nota que Silvestre tiene en su bolsillo. Guillermo rechaza la traducción de Rine Leal de la historia de los Campbell, y al mismo tiempo menciona que Campbell ha escrito un cuento supuestamente autobiográfico en que nada de lo que dice es verdad. En este libro nada es seguro.

A lo largo de Bachata, en que Arsenio Cué y Silvestre dialogan (a veces con otros personajes presentes), hay dos temas que reaparecen. Uno es la escritura, en particular la de Silvestre mencionada por Cué (pp. 404, 408), eslabón invisible entre los dos hombres y Laura Díaz. El amor transforma a los dos en gemelos (como observa Magalena, p. 395). La situación es explosiva, siguiendo ahora a René Girard y Victor Turner, porque borra diferencias y crea inestabilidad. Sólo se resuelve el problema por medio de una lucha fraternal: Uno de los gemelos tiene que perder, y esto explica la importancia de la escritura de Silvestre.

Arsenio Cué insiste tanto en hablar de la escritura de Silvestre porque a través de ella -el libro que estamos leyendo (p. 344)-Silvestre logra controlar su mundo. Aunque parezca una mise en abime, debemos recordar el valor que tiene la palabra para estos personajes: Controlar el lenguaje es controlar la vida. Cuando Cué le pregunta a Silvestre sobre las redacciones que éste hace de sus conversaciones, Silvestre al principio dice que ya no escribe. Miente, no se sabe si en defensa propia o porque es modesto: Si confiesa, su contrincante puede dejar de hablar.

Vemos que cuando los dos están hablando de personajes "contradictorios" en la literatura, Cué de repente aplica la noción a ellos mismos: "¿Y tú y yo?" Silvestre interpola sus pensamientos en ese instante entre la pregunta de Cué y su propia respuesta. Es un aparte a nosotros, los lectores, y una revelación de su técnica de protegerse por medio de máscaras:

Pensé decirle, Seamos más modestos.

"No somos personajes literarios".

"Y cuando escribas estas aventuras nocturnas?"

"Tampoco lo seremos. Seré un escriba, otro anotador, el taquígrafo de Dios, pero jamás

Łu Creador".

"Esa no es la pregunta. La pregunta es, ¿Seremos o no seremos contradictorios?"

"Lo sabremos en el último episodio" (TTT, p. 408). 
Es decir, desde el punto de vista de Silvestre, Cué nunca sabrá lo que hará de él, o, si llega a saber, será demasiado tarde para hacer nada. La ruptura entre estos hermanos conflictivos tendrá lugar en dos niveles: Silvestre se llevará a Laura y el texto. ¿Afecta esto en algo el dialogismo del libro? Si leemos el libro como escrito por Silvestre, entonces se afirma una jerarquía y un control textual. Si el texto no es monológico, no es tampoco totalmente dialógico. Este es un problema típico de todo texto literario donde el personaje central se presenta como autor de su propia narrativa -o como artista, o como escritor autobiográfico. ¿En qué momento termina la "objetividad" del narrador, o en qué momento hablan los demás personajes con su propia voz? A pesar de las protestas de Silvestre, nos preguntamos cuánto se pierde en sus redacciones/ traducciones, en particular porque la traición es el tema central del libro. Silvestre se encuentra a si mismo y deja atrás el pasado - el libro es el pasadopero para hacerlo tiene que sacrificar algo (fidelidad al lenguaje hablado) y sacrificar a alguien (Arsenio Cué).

Es importante recordar que Cabrera Infante ha hecho algo semejante consigo mismo, o con su seudónimo G. Caín, el crítico de cine. Prohibido a usar su propio nombre como periodista (publicó un cuento, "Balada de plomo y yerro", en la revista Bohemia [19 de octubre de 1952] que contenía obscenidades inglesas), Cabrera Infante publicaba bajo el nombre de Caín. En 1962, publicó una colección de sus reseñas, Un oficio del siglo $X X$, con un prólogo de Cabrera Infante. Preguntado sobre cómo quería que se leyera el libro, contestó así:

Como una novela. El Prólogo, el Intermezzo, y el Epílogo son comentarios biográficos sobre G. Caín, el crítico. Las reseñas, cu crítica, son un corpus es decir, su cuerpo. El libro entero es un rito de pasaje sobre su cuerpo muerto. Esto es una novela, ¿no te parece? (Paris Review, p. 167).

Esta cita puede servir de aviso a todos los críticos de Cabrera Infante. Tenemos que recordar que el texto nace y muere misteriosamente en él, que él controla eso que llamamos el libre juego del lenguaje. Esto puede parecer romántico, una tentativa de afirmar la presencia del autor como autoridad en su propio texto, pero estamos leyendo a un autor muy especial, un autor de sátiras. En aquella conversación entre Arsenio Cué y Silvestre en que hablan de autores y personajes contradictorios, Cué pregunta si Gargantúa fue un contradictorio. Silvestre contesta, "No, ni Pantagruel tampoco. Rabelaís si". El texto puede ser monológicoy el autor dialógico. Este es el caso de TTT: Cada lenguaje redactado es la performance de un virtuoso - Silvestre-y nunca nos deja olvidar que él es el redactor.

La ubicuidad del redactor es un tema de suma importancia en La Habana para un infante difunto. La novela ha sido traducida al inglés como Infante's Inferno, y en ambos títulos hay dos elementos en juego: el nombre del autor y la paronomasia. Es casi como si fueran una sola cosa, como si una de las 
funciones más importantes de Cabrera Infante fuera la de crear juegos de palabras. En el nivel intertextual, el título en español conecta el nombre de Cabrera Infante con la "Pavane pour une infante défunte", donde "pavane" se transforma en "La Habana" y la princesa muerta de Ravel sufre un cambio sexual para ser un "Infante difunto". Hay algo más en el título en inglés: Una alusión doble a Dante y a José Lezama Lima, que nos insta a leer el libro como una parodia de Paradiso. Pero la pregunta más grave aquí es ipor qué habla de sí mismo aquí como si estuviera muerto?

Ya lo hizo, claro, en Un oficio del siglo XX, pero Caín es un seudónimo. Para entender este acto tenemos que volver a la tradición de la consolación-confesión, al tema de la conversión. El Cabrera Infante que aparece en la novela está muerto: muerto en el tiempo y muerto porque se ha transformado en palabras escritas. Cabrera Infante habla de la dimensión erótica de esta novela como un deseo de superar la soledad:

\begin{abstract}
Después de todo, el tema central de La Habana no es sencillamente el amor sino la búsqueda de la felicidad a través del espacio vacío de la soledad. Un crítico ha llamado una de las escenas más escandalosas una "Oda a la masturbación". No es meramente el espectáculo del gusano humano copulando con su propio rabo, sino el amor en el aislamiento. Este elogio del onanismo, con el perdón de Genet y Proust, tiene lugar en un retrete vacío, pequeño, y fétido. Una celda o prisión donde el yo que ama supera su destierro en la Isla del Diablo físico y mental que llamamos la pobreza (Paris Review, p. 171).
\end{abstract}

Así que el libro entero trata de la comunicación no-verbal, aunque, paradójicamente, lo hace por medio de las palabras.

La paradoja se resuelve al final de la novela, cuando la búsqueda del protagonista para la identidad y la comunicación se desintegra. Justo en el momento en que Ámans se transforma en John Gower, donde la confesión llega a su meta y el yo que confiesa alcanza la unidad de nuevo, el narrador de La Habana se pierde totalmente. Es en aquel momento cuando nos damos cuenta de que no estamos leyendo una confesión-consolación, sino una parodia de esa forma. Así que empezamos con la identidad aquí y poco a poco la perdemos.

Al final de la novela, el narrador se hunde en el sexo de una mujer - una versión grotesca de la visión de Panurge del mundo dentro de la boca de Pantagruel en Rabelais, una versión grotesca del deseo masculino de volver al cuerpo materno. Dentro de la mujer hay un torbellino, pero el narrador encuentra allí un libro, el Viaje al centro de la tierra de Jules Verne. Lee las úl timas páginas de la novela, donde los personajes se hunden en un vórtice que los vomita de un volcán - renacen de la tierra. El narrador de La Habana describe su versión de aquel parto en la última página de la novela: 
Empecé a girar en un torbellino sin centro. Stop! Luego hubo como un choque en una falla, un estertor en la espelunca y caf libremente en un abismo horizontal.

Aquí llegamos。

Precisamente, es aquí donde llegamos. El narrador desaparece: Se transforma en un libro, el que estamos leyendo. Se ha transformado en palabras: el lenguaje liberado. La inteligencia controladora que persiste como un escritor-fantasma en TTT desaparece porque su identidad ha llegado a ser la escritura. El Cabrera Infante dialógico nace aquí en el lugar donde habríamos esperado encontrar una afirmación del yo autoritario.

Probablemente la próxima novela de Cabrera Infante, Cuerpos divinos, será su obra más dialógica porque será un homenaje a La Habana (entre 1957 y 1962) como una Babel, donde el habla libre dialógica del pueblo se opone al discurso autoritario, monológico de la política. Ya veremos. 
